International Journal of Medical Arts 2020; 2 [3]: 493-502.

Available online at Journal Website
https://ijma.journals.ekb.eg/
Main subject [Surgery]

Original article

\title{
Incidence of Esophageal Reflux after Laparoscopic Sleeve Gastrectomy for Morbid Obesity
}

\author{
Ahmed El-Sayed Orouk; Ahmed Salama Sayyouh; Nagah Atwa Salem
}

Department of General Surgery, Damietta Faculty of Medicine, Al-Azhar University, Egypt.

Corresponding author

Ahmed El-Sayed Orouk

Email: ahmed.orouk@domazhermedicine.edu.eg

Received at: march 27, 2019; Revised at: May 27, 2020; Accepted at: May 29, 2020; Available online at: May 29, 2020

DOI: 10.21608/ijma.2020.26707.1112

\section{ABSTRACT}

Background: Obesity is considered as an epidemic globally, which associated with gastroesophageal reflux disease [GERD]. Bariatrics surgery tends to reduce GERD manifestations. However, some reports noticed development of GERD after bariatric surgery; the problem which not addressed well in our community.

Aim of the work: To estimate incidence of postoperative GERD after laparoscopic sleeve gastrectomy [SG] in patients with no history of GERD symptoms prior to surgery.

Patients and Methods: Fifty morbidly obese patients who were scheduled for laparoscopic SG with no history of preoperative symptoms suggesting GERD and normal upper gastrointestinal endoscopy were included. All were assessed clinically and radiologically and followed-up for clinical or endoscopic GERD manifestations.

Results: Females were predominant [76.0\%]. Weight, body mass index and waist/hip ratio were significantly reduced after SG. Postoperative complications were leak [2.0\%], wound infection [2.0\%], bleeding [2.0\%], stricture [4.0\%] with overall rate of $8.0 \%$. Incidence of GERD was $22.0 \%$ [11 patients; 4 grade A, 5 grade $B$ and 2 grade C]. There was significant increase of Waist/hip ratio [both pre-and postoperatively] in patients who developed GERD when compared to those who did not develop GERD. In addition, there was significant increase of sleep related problems and stricture in patients who developed GERD when compared to those did not develop GERD [63.6\%, $18.2 \%$ vs $17.9 \%, 0.0 \%$ respectively].

Conclusion: The incidence of GERD after SG was $22.0 \%$. It was of mild or moderate nature, which denotes safety of SG. The procedure is also associated with marked weight reduction.

Keywords: Bariatric; Sleeve gastrectomy; Obesity; Gastroesophageal; Reflux.

This is an open access article under the Creative Commons license [CC BY] [https://creativecommons.org/licenses/by/2.0/]

Please cite this article as: Orouk AE, Sayyouh AS, Salem NA. Incidence of Esophageal Reflux after Laparoscopic Sleeve Gastrectomy for Morbid Obesity. IJMA 2020; 2[3]: 493-502.

${ }^{*}$ Main subject and any subcategories have been classified according to research topic. 


\section{INTRODUCTION}

Obesity, defined by the world health organization as a body mass index [BMI] $>30$, is an epidemic issue that has major implications on health [1].

It is estimated that $>10 \%$ of the world's populations are obese [200 million men and 500 million women], and $>20 \%$ of the worldwide population are overweight $[\mathrm{BMI}>25]$. Obesity is associated with serious complications and mortality, including, for example, cardiovascular diseases, osteoarthritis, diabetes mellitus, cancer [colon, breast, and endometrial] and gastro-esophageal reflux disease[2].

The Montreal Classification defines gastroesophageal reflux disease [GERD] as a condition that develops when reflux of stomach contents in the esophagus causes upsetting symptoms or complications ${ }^{[3]}$.

These symptoms comprise laryngitis, heartburn, dysphagia, regurgitation, and chronic cough. Prolonged exposure to acidic gastric juice can lead to stricture and Barrett's esophagus[4].

The essential provocative event in GERD is the retrograde movement of gastric juice into the esophagus $[5]$.

Bariatric surgery has been recognized as the most effective and efficient intervention to achieve marked and sustainable weight reduction in markedly obese individuals[ ${ }^{[6]}$.

Bariatric surgery is categorized as restrictive or malabsorptive. The common restrictive procedures are laparoscopic adjustable gastric banding [LAGB] and laparoscopic sleeve gastrectomy [LSG]. An LAGB is a technique that restricts the quantity of food reaching the stomach by assigning a band around the fundus that can be constrained over time with saline injections. An LSG is an innovative intervention in which a vertical partition is carried out at the greater curvature of the stomach, making restriction and reduction of the stomach pouch. Also, LSG has an action that reduces the levels of the ghrelin hormone, in addition to its restrictive mechanism[7].

Malabsorptive procedures include Roux-en-Y gastric bypass [RYGB] and biliopancreatic diversion $[B P D]$. The RYGB, is more common, and has been recognized for its substantial weight reduction in morbid obesity. It includes production of a gastric pouch that drained by a roux limb from the proximal jejunum[8]. Sleeve Gastrectomy [SG], developed in 1988 as an initial process in a staged technique to morbid obesity[9].

It was converted to a unique and sole technique by Johnston et al.[10] and a minimally invasive alternative had been established afterwards ${ }^{[11]}$. It had gained popularity since that time as a complete bariatric surgical technique ${ }^{[12]}$,

It includes resection of the greater curvature of the stomach with pyloric valve and gastroesophageal junction preservation. This keeps patency of the proximal gastrointestinal tract [GIT] and offers a restrictive and biochemical incentive for weight reduction[13].

An advantage of SG when compared to other bariatric interventions is that it does not include an anastomosis. It was originally considered a purely restrictive weight-loss technique but there is newer proof that alteration in GIT hormones plays a role. These alterations are demonstrated by a reduction in endogenous ghrelin [a hormone associated with hunger] production and reduced gastric and small bowel transit times ${ }^{[14]}$

Although, GERD is associated with obesity, and bariatric surgery usually associated with reduction of GERD, surgical treatment of obesity can result in [GERD], nutrition malabsorption, and dumping syndrome ${ }^{[15,16]}$. However, the incidence of GERD in obese patients, who not have GERD, after bariatric surgery is not well-addressed.

\section{AIM OF THE WORK}

The aim of this work is to detect the incidence of postoperative GERD as a complication of laparoscopic sleeve gastrectomy in patients with no history of GERD symptoms and with normal upper endoscopy prior to surgery.

\section{PATIENTS AND METHODS}

The present study was a prospective study, which conducted from February 2017 till August 2018. It included 50 morbidly obese [A convenient sample] patients who were candidates for laparoscopic sleeve gastrectomy with no history of preoperative symptoms suggesting GERD. Using [Narrow Band Endoscopy], preoperative upper endoscopy has been done for all cases to exclude signs of erosive 
GERD. Using the same Narrow Band Endoscopy, upper $\mathrm{GI}$ endoscopy was repeated to all patients 3 months' post-operative to detect any signs of erosive GERD.

Inclusion criteria were: 1-Both genders with morbid obesity candidate for sleeve gastrectomy, 2 Age between [20-50] years, 3- No history of preoperative GERD symptoms, and 4- Normal endoscopic findings by preoperative endoscopic assessment.

Exclusion criteria were: 1] Any patients have risk factors for GERD like smoking, history of hiatus hernia and medications like prolonged use of steroids or non-steroidal anti-inflammatory drugs [NSAIDS], 2] Patients with redo gastric sleeve, 3] Patients with positive endoscopic findings for gastritis, duodenitis or reflux, and 4] Patients refused endoscopy before or after surgery.

\section{Ethical considerations}

The study protocol was approved by Ethical and Research Committee of Al-Azhar University Hospital [New Damietta], and an informed consent was obtained from each participant after full clarification of the study, and its aims and assurance about confidentiality, and withdrawal right.

All subjects were subjected to clinical evaluation which aims to assess the degree of obesity, preoperative evaluation and detection of different complications of morbid obesity like hypertension, diabetes mellitus [DM], sleep apnea, skeletal problems, infertility, hernias, history of psychological troubles, history of reflux symptoms [acidic taste in the mouth, regurgitation, and heartburn]. In addition, Lab investigations in the form of complete blood count $[\mathrm{CBC}]$, fasting blood sugar [FBS], renal functions, liver functions, coagulation profile, lipid profile and hormonal assay, were performed. In addition, pulmonary and cardiac system were assessed clinically and radiologically. After patient counselling and consent, prophylactic clexane [enoxaparin] and prophylactic third generation cephalosporin had been delivered. In addition, compression boots for DVT prophylaxis and Foley catheter for urine output monitoring had been used, and laparoscopic sleeve gastrectomy had been completed as described by Hayes and Eid[17].
Postoperative: Regular post-operative follow-up for all patients with strict diet program had been carried out. All patients had been instructed about dietary habits that may predispose to gastritis or GERD and had been monitored for that.

Primary outcome: Patients had been asked every visit about developing any symptoms of GERD. Three months' post sleeve, upper GI endoscopy using narrow band endoscopy had been carried out to detect any signs of post-sleeve GERD. GERD had been defined according to the Montreal Consensus, GERD-like symptoms had been assessed based on a pre-designed questionnaire implemented during preoperative evaluation and at 3-month follow-up. In addition, postoperative GERD had been classified according the Los Angeles classification of esophagitis[18].

Table [1]: Symptomatic assessment [18]

\begin{tabular}{|l|l|l|l|l|}
\hline Frequency & Score & Intensity & Score & Category \\
\hline Never & 0 & None & 0 & - \\
\hline $\begin{array}{l}1 \text { or } 2 \text { days/ } \\
\text { week }\end{array}$ & 1 & $\begin{array}{l}\text { Does not cause discomfort, does } \\
\text { not interfere with daily activities }\end{array}$ & 1 & $\begin{array}{l}\text { Mild } \\
{[1-2]}\end{array}$ \\
\hline $\begin{array}{l}3 \text { or } 5 \text { days/ } \\
\text { week }\end{array}$ & 2 & $\begin{array}{l}\text { Causes some discomfort but } \\
\text { does not interfere with daily } \\
\text { activities }\end{array}$ & 2 & $\begin{array}{l}\text { Moderate } \\
{[3-4]}\end{array}$ \\
\hline $\begin{array}{l}6 \text { or } 7 \text { days/ } \\
\text { week }\end{array}$ & 3 & Interferes with daily activities & 3 & $\begin{array}{l}\text { Severe } \\
5-6\end{array}$ \\
\hline
\end{tabular}

Table [2]: postoperative GERD classification according the Los Angeles classification of esophagitis [18]

\begin{tabular}{|l|l|}
\hline Grade & \multicolumn{1}{|c|}{ Endoscopic description } \\
\hline A & $\begin{array}{l}\text { One or more mucosal break }<5 \mathrm{~mm} \text { that does not extend } \\
\text { between the tops of two mucosal folds }\end{array}$ \\
\hline B & $\begin{array}{l}\text { One or more mucosal break } \geq 5 \mathrm{~mm} \text { that does not extend } \\
\text { between the tops of two mucosal folds }\end{array}$ \\
\hline C & $\begin{array}{l}\text { One or more mucosal break that is continuous between the } \\
\text { tops of two or more mucosal folds but that involves }<75 \% \\
\text { of circumference }\end{array}$ \\
\hline D & $\begin{array}{l}\text { One or more mucosal break that involves } \geq 75 \% \text { of the } \\
\text { esophageal circumference }\end{array}$ \\
\hline
\end{tabular}

\section{Statistical analysis of data:}

The collected data had been coded and analyzed by statistical package for social science [SPSS] version 16 running on a personal computer [PC]. Numerical data had been expressed in the form of mean [a measure of central tendency] and standard deviation [SD; a measure of dispersion], while categorical data had been expressed in the form of frequency [number] and percent. Groups had been compared by independent samples [t] test if they were numerical and by Chi square test if they were categorical. Comparison between numerical variables at two different points of time had been carried out by paired samples [t] test. $P$ value $<0.05$ had been considered as the margin of significance. 


\section{RESULTS}

In the present study, fifty patients had been included; 12 of them [24\%] were males and 38 of them [76.0\%] were females. In addition, patient age ranged from 20 to 50 years; the mean age was $40.52 \pm 7.32$ years; and there was no significant difference between males and females $[41.17 \pm 7.57$ vs $40.32 \pm 7.33$ years, respectively]. The preoperative chronic medical disease among studied populations were diabetes mellitus in 16.0\%; hypertension in $22.0 \%$; sleep related problems in $14.0 \%$ and no patients had preoperative GERD.

In the present work, the mean preoperative weight was $115.86 \pm 4.42[\mathrm{~kg}]$ and at three months postoperatively, the mean weight was $96.30 \pm 2.92$ $\mathrm{kg}$; and there was significant decrease of patient's weight at three months when compared to preoperative values. Similarly, there was statistically significant reduction of $\mathrm{BMI}$ at three months postoperatively [ $\left.35.63 \pm 1.32 \mathrm{~kg} / \mathrm{m}^{2}\right]$ when compared to preoperative values $\left[42.85 \pm 1.50 \mathrm{~kg} / \mathrm{m}^{2}\right]$. Furthermore, waist/hip ratio had been reduced significantly at three months after treatment when compared to corresponding pre-operative values [0.94 \pm 0.06 vs $1.08 \pm 0.20$ respectively] [Table 3].

In the present work, the operative time had been ranged from 108 to 153 minutes; the mean values were $126.94 \pm 10.64$ minutes.

Regarding postoperative [PO] complications, $\mathrm{PO}$ leak had been reported in one patient [2.0\%], wound infection in one patient [2.0\%] and bleeding in one patient [2.0\%]. In addition, stricture had been reported in 2 patients [4.0\%]; the overall complications had been reported in four patients [8.0\%]. No patient needed revision surgery. Patients with leak, infection and bleeding had been treated conservatively, and stricture had been treated by endoscopic balloon dilation.

The incidence of postoperative GERD was $22.0 \%$ as it was reported in 11 patients out of 50 patients. The heart burn was mild in 4 of them and moderate in 6 of them. Only one asymptomatic patient had been discovered by endoscopic findings to had mild GERD [Table 4].

In the present work, there was no significant difference between males and females as regard to age, waist/hip ratio [pre- and post-operatively] and postoperative GERD. On the other hand, females had significant increase of BMI both pre- and postoperatively when compared to males $[43.22 \pm 1.37$, $35.87 \pm 1.12$ vs $41.65 \pm 1.25$ and $34.82 \pm 1.63$ respectively] [Table 5].

In the present study, patients who developed GERD when compared to those did not develop postoperative GERD were comparable as regard to age, weight, height, BMI [pre- and post-operative], operative time and duration of hospital stay. On the other hand, there was significant increase of Waist/hip ratio [both pre-and postoperatively] in patients who developed GERD when compared to those who did not develop GERD [Table 6].

In the present study, patients who developed GERD when compared to those did not develop postoperative GERD were comparable as regard categorical variables, except significant increase of sleep related problems and stricture in patients who developed GERD when compared to those did not develop GERD [63.6\%, 18.2\% vs $17.9 \%, 0.0 \%$ respectively] [Table 7].

As regard to classification of GERD according to Los Angeles classification, 4 patients [36.4\%] were grade A, 5 patients [45.5\%] were grade $B$, and 2 patients [18.2\%] were grade $C$ and none were grade D.

As regard to relation between Los Angeles classification and heart burn score, patients with grade $A$ of Los Angles classification were four in number, $25 \%$ had negative and $75 \%$ had mild heart burn score. In addition, grade $B$ were five in number, $20 \%$ of them were mild and $80.0 \%$ were moderate. Finally, grade $\mathrm{C}$ were two patients and all were moderate; and there was significant difference [Table 8].

As regard to relation between postoperative GERD and proton pump inhibitors [PPI], patients who developed GERD were distributed as the following: $36.4 \%$ had been on strict PPI use, $45.5 \%$ had been on non-strict use and $18.2 \%$ were careless about PPI use with significant increase of careless PPI use in Positive when compared to negativeGERD groups [ $18.2 \%$ vs $0.0 \%$ respectively]. In addition, patients with postoperative GERD $[n=11]$ had significant reduction of strict diet control [18.2\%] and significant increase of diet non-control [72.7\%] when compared to negative group $[30.8 \%$ and $26.0 \%$ respectively]. 
Table [3]: Comparison between pre- and post-operative weight and BMI

\begin{tabular}{|c|c|c|c|c|c|}
\hline & & Mean & SD & Paired [t] & $\mathbf{P}$ \\
\hline \multirow[t]{2}{*}{ Weight [kg] } & Preoperative & 115.86 & 4.42 & \multirow{2}{*}{35.48} & \multirow{2}{*}{$<0.001^{*}$} \\
\hline & At 3 months & 96.30 & 2.92 & & \\
\hline \multirow[t]{2}{*}{ BMI $\left[\mathrm{kg} / \mathrm{m}^{2}\right]$} & Preoperative & 42.85 & 1.50 & \multirow{2}{*}{36.87} & \multirow{2}{*}{$<0.001^{*}$} \\
\hline & At 3 months & 35.63 & 1.32 & & \\
\hline \multirow[t]{2}{*}{ Waist/hip ratio } & Preoperative & 1.08 & 0.20 & \multirow{2}{*}{6.39} & \multirow{2}{*}{$<0.001^{*}$} \\
\hline & At 3 months & 0.94 & 0.06 & & \\
\hline
\end{tabular}

BMI: Body mass index; SD: standard deviation; * significant

Table [4]: Incidence of GERD among studied populations

\begin{tabular}{|l|c|c|c|c|}
\hline \multicolumn{2}{|c|}{} & \multicolumn{3}{c|}{ GERD } \\
\cline { 3 - 5 } \multicolumn{2}{|c|}{} & No. & $\%$ \\
\hline \multirow{3}{*}{ Heart burn score } & Gegative & Negative endoscopic findings & 11 & $22.0 \%$ \\
\cline { 2 - 5 } & Positive endoscopic findings & 39 & $78.0 \%$ \\
\cline { 2 - 6 } & Mild & 4 & $2.0 \%$ \\
\cline { 2 - 6 } & Moderate & 6 & $12.0 \%$ \\
\hline
\end{tabular}

GERD: Gastroesophageal reflux disease

Table [5]: Effect of patient gender on studied variables

\begin{tabular}{|l|c|c|c|c|c|c|}
\hline \multirow{2}{*}{} & \multicolumn{2}{|c|}{ Male } & \multicolumn{2}{c|}{ Female } & \multirow{2}{*}{ P value } \\
\cline { 2 - 7 } & Mean & SD & Mean & SD & & \\
\hline Age [years] & 41.16 & 7.56 & 40.31 & 7.33 & 0.34 & 0.73 \\
\hline BMI [kg/m²] & 41.65 & 1.25 & 43.22 & 1.37 & 3.51 & $\mathbf{0 . 0 0 1}^{*}$ \\
\hline BMI at 3 months & 34.82 & 1.63 & 35.87 & 1.12 & $\mathbf{5 . 5 2}$ & $\mathbf{0 . 0 1 5 ^ { * }}$ \\
\hline Waist hip ratio & 1.16 & 0.19 & 1.05 & 0.20 & 1.50 & 0.138 \\
\hline W/H ratio 3 months & 0.97 & 0.04 & 0.93 & 0.06 & 1.90 & 0.063 \\
\hline Postoperative GERD & \multicolumn{2}{|c|}{$2[16.7 \%]$} & $9[23.7 \%]$ & 0.26 & 0.60 \\
\hline
\end{tabular}

BMI: Body mass index; SD: standard deviation; GERD: Gastroesophageal reflux disease; * significant

Table [6]: Comparison between patients developed and those not develop GERD as regard to numerical variables

\begin{tabular}{|c|c|c|c|c|c|c|c|}
\hline & & \multicolumn{2}{|c|}{ GERD } & \multicolumn{2}{|c|}{ No GERD } & \multirow[t]{2}{*}{$t$} & \multirow[t]{2}{*}{$p$} \\
\hline & & Mean & SD & Mean & SD & & \\
\hline \multicolumn{2}{|l|}{ Age [years] } & 39.00 & 8.79 & 40.95 & 6.92 & 0.77 & 0.44 \\
\hline \multirow[t]{2}{*}{ Weight [kg] } & Preoperative & 114.45 & 4.37 & 116.26 & 4.41 & 1.20 & 0.23 \\
\hline & At 3 months & 96.00 & 3.03 & 96.38 & 2.93 & 0.38 & 0.70 \\
\hline \multicolumn{2}{|l|}{ Height } & 1.64 & 0.03 & 1.65 & 0.03 & 0.95 & 0.34 \\
\hline \multirow[t]{2}{*}{ BMI [kg/m²] } & Preoperative & 42.75 & 1.53 & 42.88 & 1.51 & 0.23 & 0.81 \\
\hline & At 3 months & 35.86 & 1.13 & 35.56 & 1.38 & 0.66 & 0.51 \\
\hline \multirow[t]{2}{*}{ Waist/hip ratio } & Preoperative & 1.44 & 0.11 & 0.98 & 0.07 & 15.84 & $<0.001^{*}$ \\
\hline & At 3 months & 1.03 & 0.06 & 0.92 & 0.03 & 8.70 & $<0.001^{*}$ \\
\hline \multicolumn{2}{|l|}{ Operative time } & 127.91 & 11.83 & 126.67 & 10.44 & 0.34 & 0.73 \\
\hline \multicolumn{2}{|l|}{ Hospital stay [days] } & 3.36 & 1.21 & 3.18 & 1.10 & 0.48 & 0.63 \\
\hline
\end{tabular}

Table [7]: Comparison between patients developed and those not develop GERD as regard to categorical variables

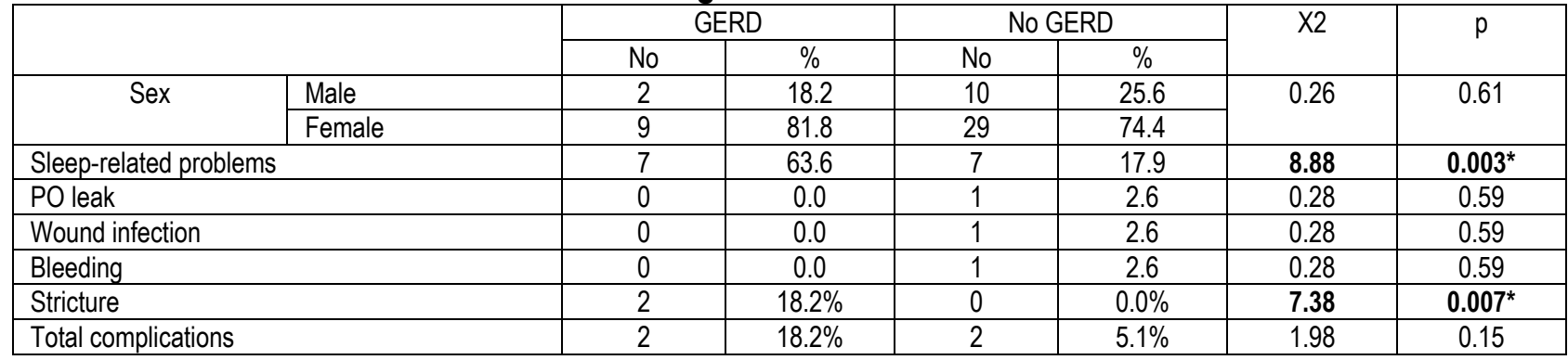

Table [8]: Relation between Los Angles and heart burn score

\begin{tabular}{|c|c|c|c|c|c|c|c|}
\hline & & \multicolumn{6}{|c|}{ LOS Angles classification } \\
\hline & & \multicolumn{2}{|c|}{ Grade $A[n=4]$} & \multicolumn{2}{|c|}{ Grade B [n =5] } & \multicolumn{2}{|c|}{ Grade C [n=2] } \\
\hline & & $\mathrm{n}$ & $\%$ & $\mathrm{n}$ & $\%$ & $n$ & $\%$ \\
\hline \multirow{3}{*}{$\begin{array}{l}\text { Heart burn } \\
\text { score }\end{array}$} & Negative & 1 & $25.0 \%$ & 0 & $0.0 \%$ & 0 & $0.0 \%$ \\
\hline & Mild & 3 & $75.0 \%$ & 1 & $20.0 \%$ & 0 & $0.0 \%$ \\
\hline & Moderate & 0 & $0.0 \%$ & 4 & $80.0 \%$ & 2 & $100.0 \%$ \\
\hline \multicolumn{2}{|c|}{ Statistics } & \multicolumn{6}{|c|}{ Test $=10.06, p=0.031^{*}$} \\
\hline
\end{tabular}




\section{Samples of Endoscopic findings}

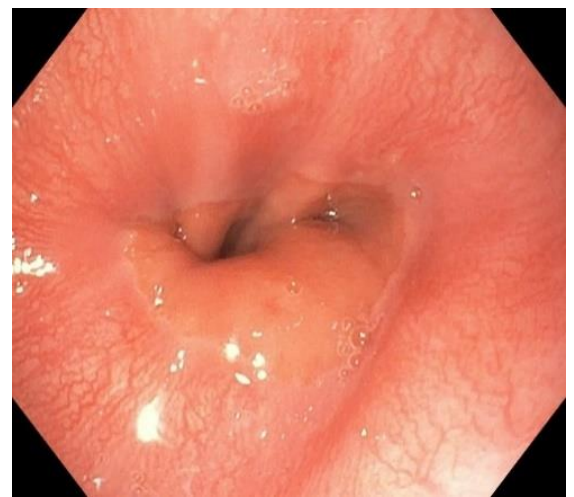

Figure [1]: Post-operative endoscopic view showing normal esophagus

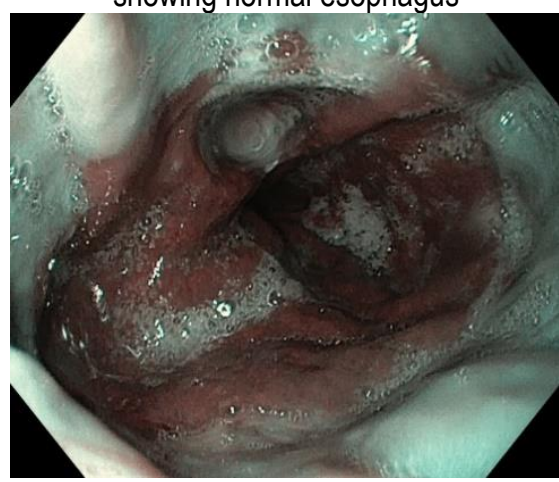

Figure [4]:Grade A reflux esophagitis [narrow band view]

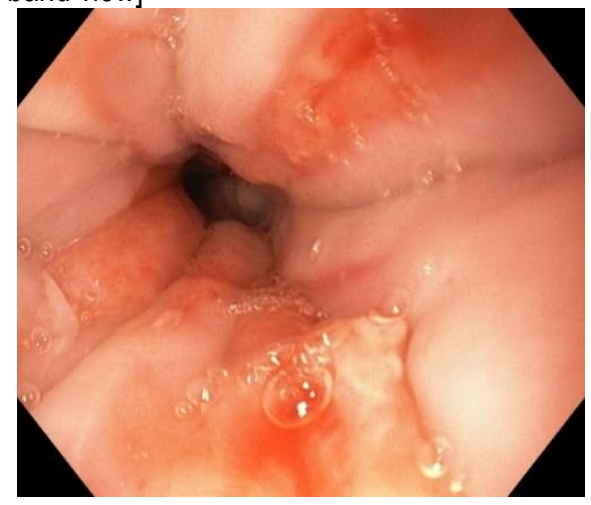

Figure [7]: Grade $C$ reflux esophagitis [endoscopic view]

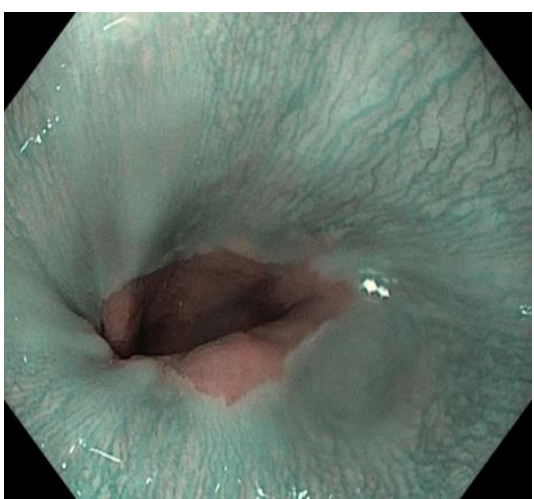

Figure [2]: Postoperative narrow band view showing normal esophagus

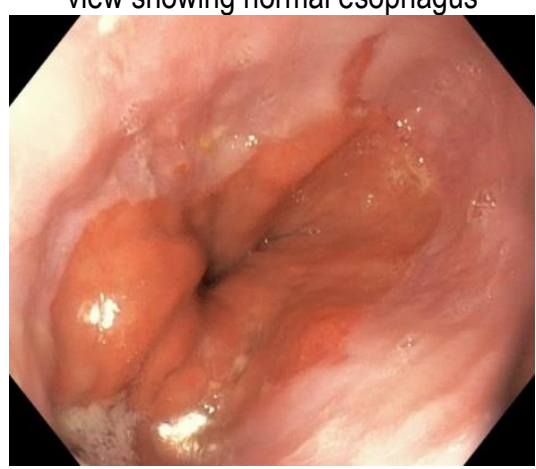

Figure [5] Grade B reflux esophagitis [endoscopic view]

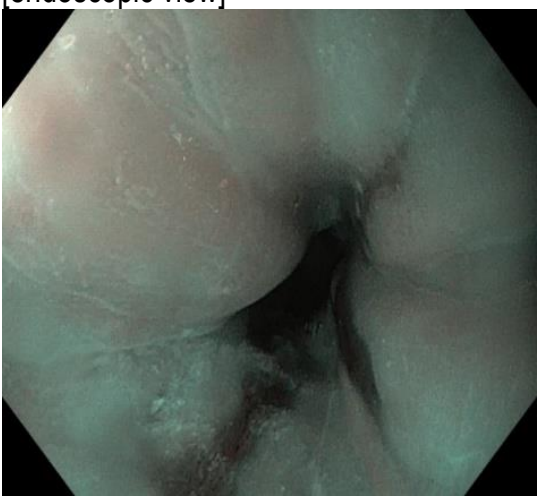

Figure [8]: Grade C reflux esophagitis [narrow band view]
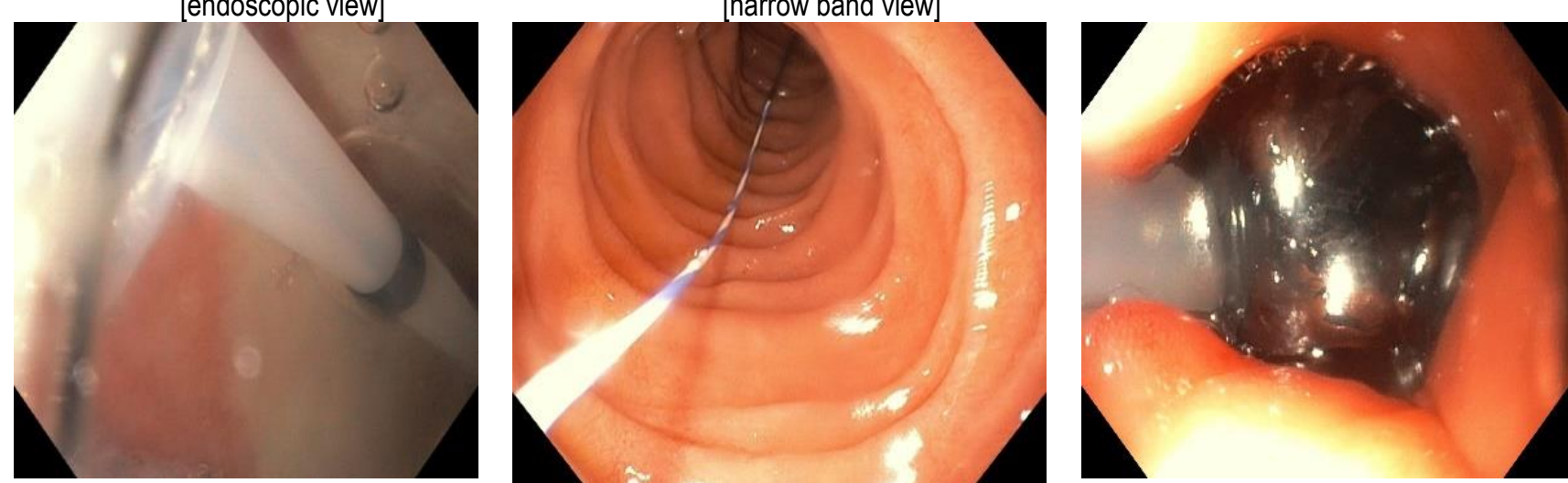

Figure [9]: Endoscoic balloon dilatation of post-operative stricure in patient with GERD grade C. 


\section{DISUCSSION}

The present study was designed to evaluate the incidence of GERD after laparoscopic sleeve gastrectomy. It included 50 patients, with no preoperative GERD, who were underwent surgical intervention and at three months postoperatively, underwent narrow band endoscopy.

In the present work, there was significant reduction of weight, BMl and waisthip ratio postoperatively when compared to preoperative values. These results are comparable to those reported by Himpens et al.[19], Pok et al.[20] who reported that, LSG was proven to be an effective weight loss surgery with significant weight loss and decrease of abdominal visceral fat. In addition, Sethi et al.[21] reported, mean waist circumference [WC] of 91 obese patients was $1.37 \pm 0.16$ meters preoperatively. At one week postoperatively, the mean WC dropped to $1.31 \pm 0.15$ meters, and there was a significant reduction in WC at three and six months postoperatively, with the mean values of $1.12 \pm 0.13$ and $0.99 \pm 0.08$ meters respectively. In addition, there was a significant reduction of waist to hip ratio at three and six months postoperatively. This indicates that, LSG as a single bariatric intervention reduces the risk of central obesity.

Weight reduction after LSG is attained by both restriction and hormonal modulation. First, decrease in the size of the stomach with sleeve resection limits distention and increases the patient's sensation of fullness [decreasing meal size]. This limitation is further enhanced by the natural band action of the intact pylorus which is preserved in SG. Second, initial proof proposes a decrease in the hunger sensation of patients undergoing SG. This may be due to reducing levels of ghrelin, a hormone stimulates hunger[22],

In the present study, the incidence of post LSG GERD was $22.0 \%$. This incidence lies with reported incidence in previous literature. Althuwaini et al.[23] reported that although the majority of the patients did not develop new-onset symptoms or even had improved symptoms of GERD after LSG, there remained a significant proportion that developed new-onset symptoms or had worsening of symptoms of GERD after SG [ranging from as high as 35.7\% for symptoms of regurgitation to as low as $16.0 \%$ for heartburn causing sleep disruption]. They concluded that some regurgitation was non-acid food regurgitation and hypothesized that regurgitation of gastric contents could have a major role in patient symptoms and might not be assessed completely by the questionnaire. Hence, the importance of using Narrow Band endoscopy in the present study. In addition, Oor et al. ${ }^{[24]}$ conducted a systematic review included a total of 24 studies reported the incidence of new-onset GERD symptoms or the incidence could be calculated, with incidence ranging from $0 \%$ to $34.9 \%$. Despite the high heterogeneity among these studies and a large disparity in outcome, they can conclude that SG could stimulate serious GERD manifestations among subjects without preoperative complaints of GERD. This is additionally reinforced by two studies providing data on variations in 24hour pH after laparoscopic SG.

Both Gorodner et al. ${ }^{[25]}$ and Rebecchi et al.[26] report on the occurrence of de novo pathologic $\mathrm{pH}$ manifestations in $36 \%$ and $10.5 \%$ of patients, respectively. Mandeville et al.[27] also reported a marked increase in GERD and PPI dependency after LSG in spite a satisfactory long-term effects on weight reduction was attained. Genco et al[228] noticed the postoperative presence of $76 \%$ of esophagitis and/or GERD symptoms and, alarmed, a 17\% of newly diagnosed Barrett's Esophagus. Therefore, GERD becomes the most important longterm complication of LSG and should be closely monitored in the future.

On the other hand, Arman et al. ${ }^{[29]}$ reported a rate of $21.4 \%$. The rate reported by Mandeville et al.[27] was $50.0 \%$ while Kowalewski et al.[30] reported a $60 \%$ prevalence rate.

Prevalence rates reported by Althuwaini et al.[23], Boza et al.[33] were $47.0 \%$ and $26.7 \%$ respectively. The possible explanation for this wide variance in prevalence could be attributed to different definitions of GERD; diagnostic methods used for confirmation of post LSG GERD and different inclusion criteria.

The development of GERD or the worsening of reflux symptoms has been reported by some authors as a late complication of LSG. Kehagias et al.[32] reported a peak of GERD symptoms in the first year which declined during the first triennium.

The intact pylorus, the removal of the antrum, the severely restricted gastric capacity and the disrupted 
motility could create stasis and induce or exacerbate reflux symptoms. When the resection is not close enough to the esophagus, a neo-fundus could form, which could also aggravate the reflux symptoms due to increased gastric acid production[33]. Additionally, the creation of a neo-fundus could worsen GERD when it is migrated intrathoracically, particularly in the existence of an un-managed hiatal hernia. However, several studies have shown that the relationship between GERD and $L S G$ is multifactorial. Such factors are an alteration of the lower esophageal sphincter pressure, reduction of gastric compliance and evacuation, increased sleeve pressure, accelerated gastric emptying and the effect of weight loss[34].

In the present work, the overall complications were $8.0 \%$; they all were mild and treated conservatively. Except two cases of stricture which needs balloon dilatation. These is comparable to previous literature. LSG is technically less demanding than LRYGB, therefore, the morbidity and mortality of this procedure are generally low, although some complications described in the literature can be serious ${ }^{[35]}$. The incidence of stricture after LSG has been estimated at $0.1-3.5 \%[33,36-37]$. Stenosis attributed to LSG may result from multiple causes [e.g., twisted gastric tube, indentation of the incisura within the gastric lumen, severe angulation of the stapler during surgery, small-sized bougie, hematomas, edema, or adhesions][38].

Fistula on the staple line $[0-7 \%$ in the literature and none in the present study] is a major postoperative complication that can lead to an important delay in operative recovery and hospitalization. This complication should be screened very rapidly, based on the classic clinical manifestations [Fever, tachycardia, abdominal and left shoulder pain, and dyspnea]. Surgical reexploration is often needed to ensure effective drainage. However, if a stage-1 fistula according to the categorization of Nedelcu et al.[35] is diagnosed, a medical and endoscopic management can be effective.

In the present work, there was no need to revision surgery. This is comparable to those reported by Nocca et al. ${ }^{[39]}$ who reported that, postoperative morbidity in the long term, including the reoperation rate is very low compared to other bariatric techniques. This is the major advantage of the LSG particularly if we consider the loss of follow-up.

In the present work, leak, wound infection, and bleeding was reported in $2.0 \%$ for each complication; and this is comparable in rate in previous literature. It was reported that, Leaks may be due to mechanical or technical errors and usually present within $48 \mathrm{~h}$ after surgery. Alternatively, leaks may be due to ischemia caused by dissection of the greater curvature using electrocautery and generally present 5-7 days after surgical intervention [40], In addition, it was reported that, early complications generally involve bleeding, gastric leak, obstruction, abscess formation, wound infection as well as all the other possible postoperative complications of major laparoscopic surgical procedures[41].

In the present study, patients who developed GERD and those did not develop GERD were comparable as studied variables except significant increase of sleep related problems in patients who developed GERD. These results are comparable to those reported by Nedelcu et al.[42] who reported that, the three main findings from their study were as follows: [1] postoperative de novo GERD after SG is frequent; [2] SG alters manometric parameters with decrease in normal contractions and increase in maximal intragastric pressure; and [3] baseline clinical and high resolution manometery [HRM] parameters do not predict postoperative GERD after SG.

In summary, results of the present study reported a $22 \%$ incidence rate of gastroesophageal reflux disease after laparoscopic sleeve gastrectomy. The procedure proved to be effective and safe. In addition, the GERD was of mild or moderate degrees confirming the safety of the procedure.

\section{Financial and Non-Financial Relationships and Activities of Interest}

None

\section{REFERENCES}

1. World Health Organization: Report on Obesity and Overweight. Geneva: The Organization; 2011. [no 311 of fact sheet series]. Available at: https://www.who.int/news-room/ fact-sheets/ detail/ obesity-and-overweight

2. Blüher M. Obesity: global epidemiology and pathogenesis. Nat Rev Endocrinol. 2019 May; 15 [5]: 288-298. [DOI: 10.1038/ s41574-019-0176-8]. 
3. Vakil N, Van Zanten SV, Kahrilas P, Dent J, Jones R; Global Consensus Group. The Montreal definition and classification of gastroesophageal reflux disease: a global evidence-based consensus. Am J Gastroenterol 2006; 101 [8]: 1900-1943. [DOI: 10.1111/j.1572-0241.2006. 00630.x]

4. Katz P, Gerson LB, Vela MF. Guidelines for the diagnosis and management of gastroesophageal reflux disease. Am J Gastroenterol 2013; 108: 308328. [DOI:10.1038/ ajg.2012.444].

5. Kellerman R, Kintanar T. Gastroesophageal Reflux Disease. Prim Care. 2017 Dec;44[4]:561-573. [DOI: 10.1016/j.pop. 2017.07.001].

6. O'Brien PE, Hindle A, Brennan L, Skinner S, Burton P, Smith A, Crosthwaite G, Brown W. Long-Term Outcomes After Bariatric Surgery: A Systematic Review and Meta-analysis of Weight Loss at 10 or More Years for All Bariatric Procedures and a SingleCentre Review of 20-Year Outcomes After Adjustable Gastric Banding. Obes Surg. 2019 Jan;29[1]:3-14. [DOI: 10.1007/s11695-018-3525-0].

7. Torres-Landa S, Kannan U, Guajardo I, PickettBlakely OE, Dempsey DT, Williams NN, Dumon KR. Surgical management of obesity. Minerva Chir. 2018 Feb;73 [1]: 41-54. [DOI: 10.23736/S00264733.17.07588-5].

8. Lyon M, Bashian C, Sheck C, Kushnir L, Slotman GJ. Outcomes following laparoscopic Roux-en-Y gastric bypass vary by sex: Analysis of 83,059 women and men with morbid obesity. Am J Surg. 2019; 217[6]: 1019-1024. [DOI: 10.1016/j.amjsurg. 2018. 11.003].

9. Hess DS, Hess DW: Biliopancreatic diversion with a duodenal switch. Obesity Surg 1988; 8 [3]: 267-282. [DOI:10. 1007/ s002689900498].

10. Johnston D, Dachtler J, Sue-Ling MH, King RF, Martin IG. The Magenstrasse and Mill operation for morbid obesity. Obesity Surg 2003; 13 [1]: 10-16. [DOI: 10.1381/ 096089203321136520].

11. Chung AY, Thompson R, Overby DW, Duke MC, Farrell TM. Sleeve Gastrectomy: Surgical Tips. J Laparoendosc Adv Surg Tech A. 2018 Aug;28[8]:930-937. [DOI: 10.1089/ lap.2018.0392].

12. Colquitt JL, Picot J, Loveman E, Clegg AJ. Surgery for obesity," Cochrane Database of Systematic Reviews 2009, no. 2, Article ID CD003641. [DOI: 10.1002/14651858].

13. Aminian A. Sleeve Gastrectomy: Metabolic Surgical Procedure of Choice? Trends Endocrinol Metab. 2018 Aug;29[8]:531-534. [DOI: 10.1016/j.tem. 2018.04.011].

14. Braghetto I, Davanzo C, Korn O. Scintigraphic evaluation of gastric emptying in obese patients submitted to sleeve gastrectomy compared to normal subjects. Obesity Surg 2009; 19 [11]: 1515-1521. [DOI:10.1007/s11695-009-9954-z].
15. Montastier E, Chalret du Rieu M, Tuyeras G, Ritz P. Long-term nutritional follow-up post bariatric surgery. Curr Opin Clin Nutr Metab Care. 2018 Sep; 21[5]: 388-393. [DOI: 10.1097/MC0.0000000000000490].

16. Savarino E, Marabotto E, Savarino V. Effects of bariatric surgery on the esophagus. Curr Opin Gastroenterol. 2018 Jul; 34 [4]: 243-248. [DOI: 10.1097/MOG.0000000000000439].

17. Hayes K, Eid G. Laparoscopic Sleeve Gastrectomy: Surgical Technique and Perioperative Care. Surg Clin North Am. 2016 Aug; 96[4]:763-71. [DOI: 10.1016/j.suc. 2016.03.015]

18. Lundell LR, Dent J, Bennett JR, Blum AL, Armstrong D, Galmiche JP, et al. Endoscopic assessment of esophagitis: clinical and functional correlates and further validation of the Los Angeles classification. Gut 1999; 45:172-80. [DOI: 10.1136/gut.45.2.172]

19. Himpens J, Dobbeleir J, Peeters G. Long-term results of laparoscopic sleeve gastrectomy for obesity. Ann Surg. 2010; 252 [2]:319-24. [DOI:
[DI]. 10.1097/SLA.0b013e3181 e 90b31].

20. Pok EH, Lee WJ, Ser KH, Chen JC, Chen SC, Tsou JJ, Chin K. Laparoscopic sleeve gastrectomy in Asia: Long term outcome and revisional surgery. Asian J Surg. 2016; 39 [1]: 21-8. [ DOI: 10.1016/j.asjsur.2015.03.006].

21. Sethi $P$, Thillai M, Singh Nain P, Ahuja A, Vayoth SO, Khurana P. Effects of Laparoscopic Sleeve Gastrectomy on Central Obesity and Metabolic Syndrome in Indian Adults- A Prospective Study. J Clin Diag Res 2017; 11[1]: PC01-PC041[DOI: 10.7860/JCDR/2017/24477. 9232].

22. Sjostrom L, Narbro K, Sjostrom CD, Larsson B, Wedel H, Lystig T, Sullivan M, et al. Effects of bariatric surgery on mortality in Swedish obese subjects. N Engl J Med. 2007;357[8]:741-52. [DOI:10.1056/NEJMoa066254].

23. Althuwaini S, Bamehriz F, Aldohayan A, Alhaidar S, Alotaibi M, Alanazi A, et al. Prevalence and predictors of gastroesophageal reflux disease after laparoscopic sleeve gastrectomy. Obes Surg. 2018; 28:916-22. [DOI: 10.1007/s11695-017-2971-4].

24. Oor JE, Roks DJ, Unlu C, Hazebroek EJ. Laparoscopic sleeve gastrectomy and gastroesophageal reflux disease: a systematic review and meta-analysis. Am J Surg 2016; 211: 250 267. [DOI: 10.1016/j.amjsurg.2015.05.031].

25. Gorodner V, Buxhoeveden R, Clemente G, Sole L, Caro L, Grigaites A. Does laparoscopic sleeve gastrectomy have any influence on gastroesophageal reflux disease: preliminary results. Surg Endosc. 2015; 29:1760-8. [DOI: 10.1007/s00464014-3902-2].

26. Rebecchi F, Allaix ME, Giaccone C, Ugliono 
E, Scozzari G, Morino M. Gastroesophageal reflux disease and laparoscopic sleeve gastrectomy: a physiopathologic evaluation. Ann Surg 2014; 260:909-15. [DOI: $\quad 10.10971$ SLA.0000000000000967].

27. Mandeville $Y$, Van Looveren R, Vancoillie PJ, Verbeke $X$, Vandendriessche $K$, Vuylsteke $P$, Pattyn P, Smet B. Moderating the enthusiasm of sleeve gastrectomy: Up to fifty percent of reflux symptoms after ten years in a consecutive series of one hundred laparoscopic sleeve gastrectomies. Obes Surg. 2017; 27:1797- 803. [DOl: 10.1007/s11695-017-2567-z.].

28. Genco A, Soricelli E, Casella G, Maselli R, Castagneto-Gissey L, Di Lorenzo N, Basso N. Gastroesophageal reflux disease and Barrett's esophagus after laparoscopic sleeve gastrectomy: a possible, underestimated long-term complication. Surg Obes Relat Dis. 2017; 13:568-74. [DOl: 10.1016/j.soard.2016.11.029].

29. Arman GA, Himpens J, Dhaenens J, Ballet $T$, Vilallonga $\mathbf{R}$, Leman $\mathbf{G}$. Long-term [11+ years] outcomes in weight, patient satisfaction, comorbidities, and gastroesophageal reflux treatment after laparoscopic sleeve gastrectomy. Surg Obes Relat Dis. 2016;12[10]:1778-86. [DOI: 10. 1016/j.soard.2016.01.013].

30. Kowalewski PK, Olszewski R, Walędziak MS, Janik MR, Kwiatkowski A, Gałązka-Świderek N, Cichoń $\mathrm{K}$, Brągoszewski J, Paśnik K. Long-Term Outcomes of Laparoscopic Sleeve Gastrectomy-a Single-Center, Retrospective Study. Obes Surg. 2018; 28[1]:130-4. [DOI: 10.1007/s11695-017-27952.].

31. Boza C, Daroch D, Barros D, León F, Funke R, Crovari F. Long-term outcomes of laparoscopic sleeve gastrectomy as a primary bariatric procedure. Surg Obes Relat Dis. 2014; 10 [6]:1129-33 [DOI: 10.1016/j.soard.2014.03.024].

32. Kehagias I, Spyropoulos C, Karamanako S, Kalfarentzos F. Efficacy of sleeve gastrectomy as sole procedure in patients with clinically severe obesity. Surg Obes Relat Dis 2013; 9: 363-369. [DOI: 10.1016/j.soard.2011. 12.011].

33. Lalor PF, Tucker ON, Szomstein S, Rosenthal RJ. Complications after laparoscopic sleeve gastrectomy. Surg Obes Relat Dis 2008; 4:33-8. [DOI:10.1016/j. soard.2007.08.015].
34. Petersen WV, Meile T, Küper MA, Zdichavsky M, Königsrainer A, Schneider JH. Functional importance of laparoscopic sleeve gastrectomy for the lower esophageal sphincter in patients with morbid obesity. Obes Surg 2012; 22: 360-366. [DOI: 10.1007/s11695-011-0536-5].

35. Nedelcu M, Skalli M, Delhom E, Fabre JM, Nocca D. New CT scan classification of leak after sleeve gastrectomy. Obes Surg 2013; 23[8]:1341-1343. [DOI: 10.1007/s11695-013-1002-3].

36. Kalaiselvan R, Ammori BJ. Laparoscopic median gastrectomy for stenosis following sleeve gastrectomy. Surg Obes Relat Dis 2015; 11:474-7. [DOI: 10.1016/j.soard.2014.06.021].

37. Levy JL, Levine MS, Rubesin SE, Williams NN, Dumon KR. Stenosis of gastric sleeve after laparoscopic sleeve gastrectomy: clinical, radiographic and endoscopic findings. Br J Radiol 2018; 91: 20170702. [DOI: 10.1259/bjr.20170702].

38. Burgos AM, Csendes A, Braghetto I. Gastric stenosis after laparoscopic sleeve gastrectomy in morbidly obese patients. Obes Surg 2013; 23:1481-6. [DOl: 10.1007/s11695-013-0963-6.].

39. Nocca D, Loureiro M, Skalli EM, Nedelcu M, Jaussent A, Deloze M, Lefebvre P, Fabre JM. Five-year results of laparoscopic sleeve gastrectomy for the treatment of severe obesity. Surg Endosc 2017; 31:3251-3257. [DOI: 10.1007/s00464-0165355-2].

40. Chivot C, Robert B, Lafaye N, Fuks D, Dhahri $A$, Verhaeghe $P$, Regimbeau JM, Yzet $T$. Laparoscopic sleeve gastrectomy: imaging of normal anatomic features and postoperative gastrointestinal complications. Diagn Interv Imaging 2013 Sep; 94 [9]:823-34. [ DOI: 10.1016/j. diii.2013. 03.017.]

41. Gagner M, Deitel M, Erickson AL, Crosby RD. Survey on laparoscopic sleeve gastrectomy [LSG] at the Fourth International Consensus Summit on Sleeve Gastrectomy. Obes Surg 2013; 23: 2013-2017. [DOI: 10.1007/s11695-013-1040-x.].

42. Nedelcu AM, Skalli M, Deneve E, Fabre JM, Nocca D. Surgical management of chronic fistula after sleeve gastrectomy. Surg Obes Relat Dis 2013; 9[6]:879-884. [doi: 10.1016/ j. soard.2013.02.010]. 